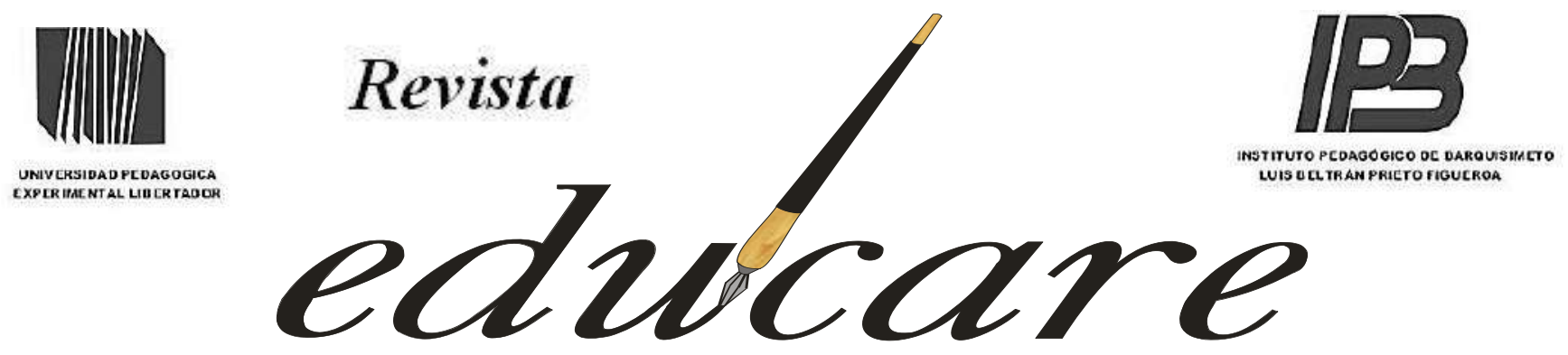

Órgano Divulgativo de la Subdirección de Investigación y Postgrado del Instituto Pedagógico de Barquisimeto “Luis Beltrán Prieto Figueroa"

RARQUISIUETO - EDO. LARA - VEMERUEA

\title{
EL IMAGINARIO SOCIAL: REFLEXIÓN CON CORNELIUS CASTORIADIS
}

\author{
THE SOCIAL IMAGINARY: REFLECTION WITH CORNELIUS CASTORIADIS
}

$I S S N: 2244-7296$

\section{Esteban Oliva *}

Universidad Pedagógica Experimental Libertador. Instituto Pedagógico Barquisimeto UPEL-IPC 


\section{EL IMAGINARIO SOCIAL: REFLEXIÓN CON CORNELIUS CASTORIADIS Esteban Oliva

\begin{tabular}{|c|c|}
\hline Ensayo & Esteban Oliva $^{*}$ \\
\hline Recibido: 29-07-2016 & Aceptado:02-12-2016 \\
\hline RESUMEN & ABSTRACT \\
\hline $\begin{array}{l}\text { Este artículo es un ensayo que tiene por } \\
\text { objetivo presentar una reflexión acerca de la } \\
\text { elucidación del filósofo Cornelius Castoriadis } \\
\text { sobre el individuo y la sociedad desde la } \\
\text { perspectiva del imaginario social. } \\
\text { Metodológicamente, la reflexión fue posibledesde } \\
\text { la hermeneúsis como procedimiento mental y la } \\
\text { exegesis dio sentido a la elucidación desarrollada. } \\
\text { La sistematizacióndeesas ideas permitióinterpretar } \\
\text { y comprender la estrecha relación entre lo } \\
\text { imaginario y la praxis social que elaboran los } \\
\text { individuos mediante sus acciones. El imaginario } \\
\text { de un conjunto humano, entonces, alude a una } \\
\text { ficción vivida por él y no a un espacio ideal, de } \\
\text { mera ficción o a un ámbito mental creado por un } \\
\text { discurso oficial. Para llegar a esta conclusión, se } \\
\text { parte de la empiria como forma de construcción } \\
\text { del mundo por parte de los seres sociales y se } \\
\text { pone en entredicho las posturas occidentales } \\
\text { tradicionales en torno al estudio de las sociedades. }\end{array}$ & $\begin{array}{l}\text { This article presents a reflection about the } \\
\text { philosopher Cornelius Castoriadis`s elucidation } \\
\text { on his perspective about the individual and } \\
\text { society from the imaginary point of view. } \\
\text { Since, from the hermeneusisas a mental } \\
\text { procedure and the elucidation as an analysis } \\
\text { technique, there are shown a group of ideas } \\
\text { which allows the interpretation and the } \\
\text { comprehension of the close relation between } \\
\text { the imaginary and the social praxis that the } \\
\text { individuals develop through their actions. The } \\
\text { imaginary of a human group deals with a } \\
\text { fiction lived by himself and not with an ideal } \\
\text { space, of a mere fiction or a mental } \\
\text { environment created by an official speech. To } \\
\text { come up to this conclusion, it is first taken into } \\
\text { account the empiria,as a world constructing } \\
\text { way by means of the social beings and the } \\
\text { western traditional theories are in judgment in } \\
\text { relation to the societies studies. }\end{array}$ \\
\hline iedad, imaginario. & Key words: Individual, society, imaginary \\
\hline
\end{tabular}

\footnotetext{
"Profesor de Inglés. Adscrito al Departamento de Idiomas Modernos UPEL-IPB. Magíster en Gerencia Educacional, Yacambú. Magíster en Educación, Mención Investigación, UPEL-IPB. Especialización en Experto en e-learnig, Convenio FATLA-UPEL Draco 2012. Candidato a Doctor en Cultura Latinoamericana y Caribeña (UPEL-IPB Venezuela), aprobada la presentación pública de su estudio doctoral: "Imaginario Social de los Llanos Occidentales de Venezuela". Miembro investigador activo de la Red Iberoamericana de Investigación en Imaginarios y Representaciones (RIIR). cosmosorden@yahoo
} 


\section{EL IMAGINARIO SOCIAL: REFLEXIÓN CON CORNELIUS CASTORIADIS \\ Esteban Oliva \\ (PP 100-115)}

\section{INTRODUCCIÓN}

Este artículo, de valía social y filosófica, es una reflexión que trae a discusión el imaginario, propuesto por Cornelius Castoriadis, un fenómeno que da cuenta de un ideario creado a partir dela acción del hombre en tanto que ser en conexión directa con su entorno socio-cultural. En ese fenómeno subsisten realidades planteadas desde el desarrollo humano, mediante la internacionalización de formas culturales, por el hecho de que los imaginarios sociales representan la consciencia cotidiana del individuo para repensar su propia cultura.

Castoriadis (2003) manifiesta que:

El hombre no puede existir sino definiéndose cada vez como un conjunto de necesidades y de objetos correspondientes, pero supera siempre estas definiciones $-\mathrm{y}$, si las supera ... es porque sale de él mismo, porque él las inventa (no en lo arbitrario ciertamente, siempre está la naturaleza, el mínimo de coherencia que exige la racionalidad, y la historia precedente), porque, por lo tanto, él las hace haciendo y haciéndose, y porque ninguna definición racional, natural o histórica permite fijarlas de una vez por todas..." (p. 235).

En atención al autor, la imaginación del individuo bien puede ser una potencia con la cualidad de ser en sí misma una representación y -simultáneamente- una condición para la creación de otras representaciones e imaginarios de esos individuos en el mundo. Ese espacio social es instituido por el individuo en la medida que construye su existencia en una permanente definición desde la imaginación de sí mismo. La manifestación de los imaginarios sociales en fenómenos sociales llenos de significaciones es lo que articula y constituye a la sociedad en particular y determina su cultura en relación con otras latitudes. Los imaginarios sociales son creación del hombre social e involucran al mundo real y concreto y al accionar humano diario.

El hacer social, entonces, es tangible en creaciones genuinas de las acciones humanas constituyéndose en un imaginario, no en concepciones abstractas ni teóricas; sencillamente las significaciones pertenecen al plano del hacer, de lo efectivo, de la praxis, de la actividad; en una palabra, pertenecen a la vida misma. Desde esta perspectiva, el individuo es un ser humano de sueños, de pensamientos, de acción y de creación imaginaria. En este sentido, creación es la representación de las acciones humanas; en una localidad existen distintos imaginarios y el individuo que habita en ella asume una imaginación radical, de suerte que sus acciones traducen el vínculo mediante el cual el núcleo originario es plasmado como significado y significante a partir de lo imaginario (Castoriadis, ob. cit.). 


\section{EL IMAGINARIO SOCIAL: REFLEXIÓN CON CORNELIUS CASTORIADIS \\ Esteban Oliva \\ (PP 100-115)}

Una sociedad es un universo de imaginarios de construcción discursiva elaborado a partir de dos visiones: la primera es la visión de un discurso oficial y la segunda nace a partir de las vivencias del contingente de sus lugareños; pero, a su vez, esta última visión deja entrever una cosmovisión desde las manifestaciones culturales propias y vivenciales del ser social. Ello viene a ser una creación individual y genera lo compartida en cuyo seno brotan elementos culturales que definen el sentido de pertenencia y del ser identitario del hombre.

Desde esta perspectiva el abordaje teórico de los imaginarios de un colectivo representa un proceso de comprensión y hallazgo de la creación humana; ello porque los imaginarios están insertos en la saber de los pueblos. Por lo tanto, con la intencionalidad de construir una interpretación de los procesos que permiten la formación del imaginario es pertinente, en primer término, abordar la Teoría de Imaginario Social de Castoriadis principalmente desde su obra $L a$ Institución Imaginaria de la Sociedad (2003). La idea de este filosofo da un giro al pensamiento occidental, al cual cuestionan y ante el cual propone otros modos de pensar lo pensable; quien suscribe está convencido de que el filósofo hace un aporte interesante a la investigación social. De modo que, a continuación, se elabora una síntesis comentada de los basamentos epistemológicos que sustentan el presente artículo.

\section{EL IMAGINARIO: REFLEXIÓN EPISTEMOLÓGICA CON CORNELIUS CASTORIADIS}

Al hacer una revisión crítica de la obra de Castoriadis (2003), se hace arduo el proceso de comprensión de qué es lo imaginario. Es impreciso; refiere no sólo a un espacio ideal, de ficción, a un ámbito mental sino que también versa sobre la realidad efectiva social, a la acción, a la praxis social. Ello invita a revisar la noción de lo imaginario y sus alcances para interpretar y comprender si lo imaginario aplica a la praxis social que elaboran los moradores de los pueblos mediante sus acciones (que alude a una ficción vivida por ellos) y no atañe exclusivamente a un espacio ideal, de mera ficción o a un ámbito mental creado por un discurso oficial.

Desde sus primeras ideas sobre imaginario, Castoriadis (ob. cit.) explica que la palabra imaginario no es un reflejo o imagen de, tesis defendida por la concepción heredada de la ciencia. Al respecto afirma:

Lo imaginario no es a partir de la imagen en el espejo o en la mirada del otro. Más bien, el "espejo" mismo y su posibilidad, y el otro como espejo, son obras de lo 


\section{EL IMAGINARIO SOCIAL: REFLEXIÓN CON CORNELIUS CASTORIADIS \\ Esteban Oliva \\ (PP 100-115)}

imaginario...Los que hablan de "imaginario", entendiendo por ello lo "especular", el reflejo o lo "ficticio", no hacen más que repetir, las más de las veces sin saberlo, la afirmación que les encadenó para siempre a un subsuelo cualquiera de la famosa caverna: es necesario que este mundo sea imagen de alguna cosa (p.12).

Sin lugar a dudas la cita anterior evidencia que para la concepción heredada de la ciencia, el campo del imaginario y de la imaginación fue concebido tanto reflejo de, imagen de, representación de algo. Desde esta óptica del pensamiento científico, lo imaginario es una fuente de falsedad, las opiniones son cuestionadas, la verosimilitud del concepto imaginario es puesta en entredicho por Castoriadis puesto que, se sobreentiende en su criterio, los pensadores manifiestan poco conocimiento de la realidad; en otras palabras, en la definición del concepto imaginario, abunda la indefinición, la indeterminación. Castoriadis (ob. cit.) piensa que la concepción heredada de la ciencia en el territorio del ser se fundamenta en la razón como origen de la verdad, de la certeza, de la lógica del conocimiento de las cosas, de la determinación, de las definiciones, porque el ser es.

A partir de esa noción, la postura de Castoriadis (ob. cit.) contradice la afirmación de la concepción heredada de la ciencia, consecuentemente, lo imaginario en un reflejo de la realidad, es una afirmación falsa en tanto que lo imaginario y la imaginación no son ni reflejo de, ni imagen de, ni representación de, sino, por el contrario, lo imaginario y la imaginación constituyen un "es"; el imaginario es, desde luego, un espacio cuyo ser se caracteriza por la creación espontánea incesante y novedosa desde la nada, el azar, la contingencia, el abismo, el hallazgo, el hacer, la acción, las significaciones imaginarias sociales que se mueven en el campo de la indeterminación, de lo no definido, del caos, porque tales aspectos también "son". Castoriadis (ob. cit.) piensa que estas categorías intervienen de manera específica en la formación de la sociedad como institución: lo que produce realidad y racionalidad es el vínculo entre lo imaginario y la imaginación y no únicamente la razón lógico formal postulada por la tradición filosófica occidental.

En este sentido, Castoriadis (1998b) piensa que lo imaginario es un ámbito de creaciones espontáneas de cada individuo como sujeto psíquico, de la colectividad e institución social; y también señala que lo imaginario consiste en la creación incesante esencialmente novedosa de los individuos desde lo psíquico y lo social, pues lo social es el área donde se reúne lo individual y lo colectivo. 


\section{EL IMAGINARIO SOCIAL: REFLEXIÓN CON CORNELIUS CASTORIADIS \\ Esteban Oliva \\ (PP 100-115)}

Asimismo, Castoriadis (1998b) explica que lo que intenta "no es una teoría de la sociedad y de la historia, en el sentido heredado del término teoría. Es una elucidación y esta elucidación, incluso si asume una faceta abstracta, es indisociablemente de un alcance y de un proyecto político..." (p. 113). Con esta idea se separa del pensamiento heredado de la ciencia y presenta de alguna manera el "hacer social histórico" desde el hacer y la acción humana (Castoriadis, 2003, p.10).

Así entonces, Castoriadis (ob. cit.) nos presenta un panorama teórico donde toda comunidad, en un espacio y tiempo determinado, tiene sus imágenes con las cuales ofrece significaciones de la realidad. El discurso oral de los pueblos revela ese fenómeno y, al hacerlo, revela el sentido del hombre en su cotidianidad en relación con la manifestación racional y/o pasional que acompañan toda aventura humana.

El orden que construye las significaciones es el imaginario que deviene de la creación en tanto acción reflejada en imagen; este orden contempla tanto las conexiones causales establecidas por el pensamiento heredado como aquellas que van más allá de éstas y deviene de "un conjunto infinito de posibles y de un conjunto infinito de imposibles dados...de una sola vez"(Castoriadis, ob. cit., p.78); las significaciones constituyen un campo fértil para desarrollar la praxis social en tanto creación en la que tiene lugar el azar, lo espontáneo, lo realizable, lo verosímil, lo viable, lo que puede hacerse y es visible en lo imaginario a través de imágenes, figuras, formas, símbolos. La combinación de la razón y lo imaginativo en un espacio de infinitas conexiones cuyo vínculo es posible por la conexión de todas las categorías anteriormente nombradas. De esta forma, la praxis social, los hechos y las significaciones generan una realidad en la cual el hombre es hacedor de transformaciones histórico-sociales.

Al respecto Castoriadis (2003) explica que:

La praxis es, ciertamente, una actividad consciente y no puede existir más que en la lucidez; pero es algo del todo distinto a la aplicación de un saber previo (y no puede justificarse por la aplicación de semejante saber -lo cual no quiere decir que no puede justificarse). Se apoya sobre un Saber, pero éste es siempre fragmentario y provisional. Es fragmentario, porque no puede haber una teoría exhaustiva del hombre y de la historia; y es provisional, porque la praxis misma hace surgir constantemente un nuevo saber, pues hace hablar al mundo en un lenguaje a la vez singular y universal. Es por ello por lo que sus relaciones con la teoría, la verdadera teoría correctamente concebida, son infinitamente más íntimas y más profundas que las de cualquier técnica o práctica "rigurosamente racional" para la que la teoría no es más que un código de prescripciones muertas que no puede jamás encontrarse, en lo que maneja, con el sentido (p. 136). 


\section{EL IMAGINARIO SOCIAL: REFLEXIÓN CON CORNELIUS CASTORIADIS \\ Esteban Oliva \\ (PP 100-115)}

En esta exposición se evidencia que la praxis refiere a la experiencia, a lo real efectivo social, a la actividad humana en permanente dinamismo, a lo imaginario, no a la teoría formalcientífica. Por ello, lo imaginario puede emerger de lo empírico de la experiencia y accionar cotidiano. Según Rorty (1993) en su análisis de la teoría, antes descrita destaca como Castoriadis (ob. cit.) fundamenta su investigación en la praxis, la creación, la contingencia, el azar; su propuesta es que el vínculo entre lo imaginario y la imaginación producen la realidad, porque la psique y la sociedad constituyen un binomio indisoluble. Ese binomio es generador de las instituciones donde la potencialidad de lo imaginario está representada en el hacer, la acción, la potencialidad de crear un nuevo proyecto de futuro donde la cotidianidad y la lucha por la vida real son fundamentales.

La teoría de imaginario social de Castoriadis (ob. cit.) cuestiona, problematiza, interroga a la praxis para interpretar a la sociedad porque “...la acción de los hombres es el único lugar en el que las ideas y los proyectos pueden adquirir su verdadera significación” (p.113).

Además, afirma que:

Llamamos praxis a ese hacer en el cual el otro, o los otros, son considerados...seres autónomos y...el agente esencial del desarrollo de su propia autonomía. La verdadera política, la verdadera pedagogía, la verdadera medicina, puesto que han existido alguna vez, pertenecen a la praxis. En la praxis hay un por hacer, pero este por hacer es específico: es precisamente el desarrollo de la autonomía del otro o de los otros... (el desarrollo de la autonomía)... (el ejercicio de esta autonomía)...(pp. 129 y 130).

En este sentido, la autonomía es intención y motivación, que mueve a los individuos y al colectivo a activarse socialmente. Castoriadis (ob. cit.) habló de un imaginario en el cual el sentido de las significaciones consiste en el desarrollo y ejercicio de la autonomía del individuo y de la colectividad.

Castoriadis (ob. cit.) entiende la autonomía desde la máxima del psicoanálisis, el aforismo, planteado por Freud (1934) "WoEshwar, sollIchwerden” (p. 234). A lo que refiere es que el Yo, lo consciente, es autónomo, porque tiende a auto-regularse mediante la acción. El ello, lo inconsciente, es alienación, legislación dada por otro; un otro que está en mí, compuesto de instintos, deseos, y todos los valores, normas, a partir de las cuales el individuo es formado. A ese

‘“En lugar del Ello, debo devenir Yo”. Traducción del alemán al español por Esteban Oliva (2016). 


\section{EL IMAGINARIO SOCIAL: REFLEXIÓN CON CORNELIUS CASTORIADIS \\ Esteban Oliva \\ (PP 100-115)}

concepto adiciona: "La autonomía se convierte entonces en: mi discurso debe tomar el lugar del discurso del Otro, de un discurso que está en mí y me domina: habla por mí...” (pp. 174 y 175). Es decir, la autonomía no queda en sólo discurso sino en la autenticidad del individuo ante los prejuicios de otros.

Dentro del interior del hombre confluyen lo auténtico y lo no auténtico. Lo no auténtico configura lo ajeno a su autenticidad y lo seduce desde antes de su nacimiento. Para Castoriadis (2003), "Lo esencial de la heteronomía o de la alienación...en el nivel individual, es el dominio por un imaginario autonomizado que se arrogó la función de definir para el sujeto tanto la realidad como su deseo" (p. 175). El autor entiende que la heteronomía constituye a lo no auténtico que a su vez está conformado por lo ya establecido: los padres, las instituciones, la sociedad, las normas, los valores, la religión y, además, por los instintos, deseos, miedos.

La autonomía es ejercida en la medida en que se opone, transforma o modifica lo establecido, lo heterónomo; esto sólo es posible en la praxis social, con la imaginación, con la creación, con el individuo y el colectivo. La autenticidad es praxis en tanto el hombre es capaz de crear y constituir su propio yo, limpiar su yo de todos aquellos aspectos ajenos a su autenticidad. De las acciones emerge la autonomía, un hacer que forja cada individuo junto con el colectivo en la medida que desarrolla la imaginación.

En síntesis, Cornelius Castoriadis concibe su estudio sobre lo imaginario a modo de un por hacer, un por construir, el imaginario está allí, por organizar y moldear, es la realidad efectiva social y sólo los hombres con su potencia creadora, materializada en acciones, darán forma a este campo: allí la praxis social genera las significaciones que darán sentido al hacer cotidiano.

\section{LO IMAGINARIO: HACIA UNA PROPUESTA METODOLOGÍA PARA LA CREACIÓN CIENTÍFICA EN EL CAMPO HISTÓRICO-SOCIAL}

Desde estas páginas, quien escribe propone pensar los imaginarios en relación con su actividad creadora de eidos* mostrando su fuerza creadora en el campo socio-histórico. Lo imaginario como institución aparece, como respuesta a fenómenos sociales que emergen de la dinámica social, con unas características que lo hacen particular y diferente a otra institución. Esa

\footnotetext{
${ }^{\ddagger}$ El eidos aquí es entendido como imágenes que ofrece la realidad cuando es contemplada con los sentidos.
} 


\section{EL IMAGINARIO SOCIAL: REFLEXIÓN CON CORNELIUS CASTORIADIS \\ Esteban Oliva \\ (PP 100-115)}

adecuación singular deviene de lo histórico-social, por consiguiente, los modos de cambios y transformación son creaciones particulares e individuales de cada praxis social. La experiencia, las significaciones sociales imaginarias, los estilos de vida y los fenómenos sociales son únicos en cada particularidad social. De allí se comprende que la diferencia entre las distintas sociedades como instituciones históricas está representada en la adecuación particular del imaginario ante los fenómenos sociales de cada colectividad.

Según Castoriadis (2003), la reflexión sobre la sociedad y la historia han tenido lugar desde lo lógico y lo ontológico, comprendiendo con ello una "suma y secuencia de acciones de una multiplicidad de sujetos, determinadas por relaciones necesarias y a través de las cuales un sistema de ideas se encarna en un conjunto de cosas" (p.12); es evidente una reducción de lo social y lo histórico a lo racional formal, a la idea o al concepto. Cuando eventualmente puede decirse, que cada ciudad, pueblo o nación elabora un determinado constructo en una especie de transición entre lo psicológico individual y lo colectivo; así Edward Rutherfurd (2000), en su novela Londres, describe cómo ha ido conformándose un conjunto de representaciones sobre la ciudad en un recorrido por más de 2000 años, que incluye su fundación mítica y los procesos religiosos y culturales a partir de templos, instituciones educativas, militares u otras e igualmente otras metrópolis o áreas del mundo.

Castoriadis (ob.cit.) va a demostrar que lo histórico y lo social no responden a conceptos, a lo determinado, ni a categorías trascendentales, ni a la razón lógica. La historia y lo social son una misma cosa y refiere a ello como lo histórico-social; por ello el imaginario proyecta lo socialhistórico y no se opone a lo real, sino a lo racional. En este sentido, lo imaginario tiende a cuestionar las nociones del pensamiento heredado que explican al ser como determinado y de la lógica como la que atribuye coherencia a esta determinación. En este sentido el ser de lo histórico social constituye a sí mismo un eidos que surge de la acción de la sociedad sobre los fenómenos sociales que experimenta.

La investigación de Castoriadis(ob. cit.) resalta que los individuos ya son sociales y llevan lo social en sí; los individuos y el colectivo son elementos que hacen a una sociedad, son intrínsecos a lo social; las relaciones entre individuos son relaciones sociales entre individuos sociales; las relaciones con las cosas son relaciones sociales con objetos sociales; los individuos, las cosas y las relaciones que se dan entre éstos son instauradas por la praxis específica y 


\section{EL IMAGINARIO SOCIAL: REFLEXIÓN CON CORNELIUS CASTORIADIS \\ Esteban Oliva \\ (PP 100-115)}

particular que realiza cada sociedad; los ámbitos de la actividad social no son separables y existen en función de una institución histórico-social particular.

En opinión que quien suscribe, los elementos que constituyen la cultura de una región en un momento dado (la política, la religión, la economía, la educación, la familia, la relación hombremedio, la música) son creaciones sociales específicas, producto de la praxis de cada sociedad en particular, y es por la praxis social que existen diferencias entre las culturas de las sociedades.

La praxis como creación representa la forma social que los hombres están construyendo. La magia de esta praxis consiste en generar respuestas nuevas a antiguos y a nuevos fenómenos sociales, es decir, en repensar nuevas situaciones; en síntesis, inventar un nuevo orden social a partir de la irrupción de la voz disidente.

La sociedad se instituye constantemente como una forma diferente en la medida en que constituye relaciones sociales nuevas. Aquello en lo cual se recrea lo social y la manera en que se despliega al surgir la creación, se constituye en cada momento de forma inédita; en otras palabras, lo social es la manifestación de un tipo específico de praxis humana. Para Castoriadis (ob.cit.), lo social:

Hemos de pensarlo como un magma, e incluso como un magma de magmas, con lo que no quiero decir el caos, sino el modo de organización de una diversidad no susceptible de ser reunida en conjunto, ejemplificada por lo social, lo imaginario o lo inconsciente (p.34).

El imaginario social es un "magma de significaciones imaginarias sociales" encarnadas en instituciones. Desde esta premisa, lo imaginario regula el decir y orienta la acción de los miembros de esa sociedad, en la que determina las maneras de pensar, sentir y desear. En definitiva, ese mundo es esencialmente histórico. En efecto, toda sociedad contiene en sí misma una potencia de alteridad. Siempre existe según un doble modo: el de "lo instituido" (estabilización relativa de un conjunto de instituciones) y el de "lo instituyente" (la dinámica que impulsa su transformación). Por ello resulta conveniente hablar de lo "social-histórico (Castoriadis, ob. cit.).

Dado así el imaginario social, se comprende que lo social-histórico es el campo donde es posible la potencia creativa del ser humano derivada de la acción. Este campo es contentivo de la posibilidad de alteridad, porque para Castoriadis (2003)

...la historia no es secuencia determinada de lo determinado, sino emergencia de la alteridad radical, creación inmanente, novedad no trivial..." (p.38). Lo esencial a la historia es la actividad humana creadora y sus productos son innovación e invención. 


\section{EL IMAGINARIO SOCIAL: REFLEXIÓN CON CORNELIUS CASTORIADIS \\ Esteban Oliva \\ (PP 100-115)}

Sólo a partir de la acción como creación, Castoriadis (ob. cit.) plantea que se puede hacer historia y definir el tiempo que se encuentra en la historia como la manifestación del surgir de algo distinto a aquello que es la expresión de lo nuevo y la constitución de lo recién elaborado y por ello sostiene que: "El tiempo es emergencia de figuras distintas...(p. 51).

Este modo de hacer historia responde a que las relaciones emprendidas por cada sociedad en particular con su pasado y con su presente; a partir de ello brotan cada vez situaciones nuevas, distintas a las establecidas; no son actualizaciones de escenarios pensados anticipadamente. El tiempo como valor agregado de lo histórico social consiste en el surgimiento de situaciones distintas a las establecidas, en el aparecer de otras formas sociales, de nuevas significaciones e instituciones. Para Castoriadis (ob.cit.): "el tiempo es la alteridad, la condición que permite constituir cambios en las formas o modelos dados, la dimensión que ofrece la posibilidad de que lo establecido pueda transformarse en otra situación" (p. 51). Sobre el tiempo como alteridad se convierte en alteración al mover las fuerzas sociales hacia la transformación.

De acuerdo con lo expuesto, puede decirse que la idea central de Castoriadis consiste en concebir lo histórico-social como la praxis social creativa; es decir, un por hacerse que manifestado en una forma de institución específica en un momento dado. Es necesario develar como los hombres héroes de carne y hueso, que nacen, sufren y mueren (De Unamuno, 1967), son capaces de darle vida a algo y presentarlo de forma inédita. Este dar a luz consiste en reconocer la capacidad que tienen los individuos y el colectivo de producir escenarios nuevos que no son imitaciones de cosas ya hechas, establecidas y existentes.

Este hacer, producir, acción y efecto de instituir o constituir, no son a partir de, ni imitación de, ni según tal o cual norma. Los imaginarios devienen del hacer haciendo, de la praxis social en cuestión que marca una ruptura, una escisión con lo establecido para convertirlo en otro. Esta idea reconoce que el hombre constituye lo nuevo y no copia modelos prefijados, porque su actividad irrumpe en lo establecido para transformarlo y cambiarlo. La praxis social es invención, creación, imaginación, alteridad-alteración.

El tiempo como alteridad-alteración constituye la dimensión vital que une lo social y lo histórico porque es la presencia cierta de la praxis tanto creación. Lo social-histórico es la experiencia de vida específica que surge en un momento dado. Dicho de otro modo, es la vida social efectiva inseparable de la experiencia como presencia que aparece en un tiempo dado con el talante de una práctica inédita. 


\section{EL IMAGINARIO SOCIAL: REFLEXIÓN CON CORNELIUS CASTORIADIS \\ Esteban Oliva \\ (PP 100-115)}

La experiencia junto con las significaciones imaginarias (la institución, el hacer, la acción) conforman el ser social. La aparición de la praxis como un modelo específico de creación en un momento dado es lo que Castoriadis refiere como lo histórico-social. Por consiguiente, lo histórico-social es el ámbito de la creación humana, donde los individuos y el colectivo en el hacer haciendo y haciéndose instauran nuevas relaciones sociales en un momento dado, lo imaginario (Castoriadis, ob. cit.).

Luego de la anterior reflexión, se puede decir que la sociedad como institución históricasocial es la praxis social instituyente. Se presenta como una institución específica con ser propio y autónomo que se antepone a toda la tradición que representa el pensamiento estructuralfuncionalista que jamás ha pensado el ser desde lo social, incluso de lo cultural (Santiago, 2000). Para evidenciar las reflexiones hasta acá puntualizadas entre estas páginas, a continuación se presenta un ejemplo de la aproximación al estudio de lo imaginario en un contexto particular. En este caso, se trata de la ciudad Guanarito, Estado Portuguesa, Venezuela, en el cual -gracias al reciente contacto del autor de estas líneas con esa localidad- se puede apreciar la visión del pueblo desde dos voces: la de la crónica o referencia histórica oficial y aquella de sus moradores originarios.

Al referir parte de la historia local, la institución muestra una forma oficial para que lo imaginario pueda ser captado por los propios individuos que lo producen; pero se contrapone a las vivencias de sus coetáneos. Así, la institución imaginaria histórico-social durante la fundación hispana del Pueblo de Misión "Nuestra Señora de la Paz de Guanarito" no es la misma que aquella de las formaciones económicas de la sociedad aborigen originaria; esta última responde al área cultural Arawacos Occidentales (Acosta Saignes, 1983). La institución imaginaria históricosocial independentista en Venezuela se distancia totalmente del modo de vida practicado en la época colonial (De Armas Chitty, 1993). Cada una de estas instituciones expresó una praxis social particular y única en el tiempo. Castoriadis (2003) plantea que el tiempo imaginario es:

...de hacer...debe ser instituido...como continente de singularidades no determinables de antemano, como posibilidad de la aparición de lo irregular, del accidente, del acontecimiento, de la ruptura de la recurrencia. En su institución, debe preservar o cuidar de la emergencia de la alteridad como posible, y ello intrínsecamente (p. 82).

La praxis del hacer social es irregular, accidentada y alterante. No es lineal, ni regular, ni repetitivo. De esa manera, lo histórico-social va unido y no separado, puesto que la sociedad se 


\section{EL IMAGINARIO SOCIAL: REFLEXIÓN CON CORNELIUS CASTORIADIS \\ Esteban Oliva \\ (PP 100-115)}

da como un modo específico de praxis humana en un momento dado. Esta praxis es la construcción de un tipo de experiencia por los individuos que aparece de forma novedosa.

Para quien reflexiona entre estas líneas, lo histórico-social es un enigma interminable, porque es un por hacer en un horizonte de infinitas posibilidades que ofrece las condiciones para que emerja la alteridad alteración creativa en la praxis social. Al ser una creación novedosa, no está prefijada o predeterminada, sino que aparece a modo de un magma instituyente que puede ser constructivo o destructivo. El planteamiento de Castoriadis (1998a) consiste en que lo imaginario como sociedad "es magma y magma de magmas..." (p. 106); es decir, remite a la inserción en la red de las significaciones imaginarias.

La sociedad remite a todas las significaciones imaginarias que emergen de ella y son atendidas en el tejido simbólico del hacer haciendo. Todo fenómeno social que aparece en la sociedad está investido de significación; es decir, que aquello que aparece es notorio, se distingue por alguna circunstancia, se expresa de tal forma que se muestra de forma importante o algo que es necesario saber. Y ¿Cuáles son esos fenómenos sociales? Todo lo que emerge de la praxis social: religión, política, derecho, inseguridad, medios de comunicación, internet, entre otros. Cada una de ellos tiene un significado para cada hombre, para cada colectividad, para cada sociedad.

Por consiguiente, Castoriadis (ob.cit.) expresa que: "La institución de la sociedad es institución de un mundo de significaciones que es evidentemente creación como tal, y creación específica en cada momento" (p.106). Al ser creación esencialmente novedosa constituye un movimiento permanente que se manifiesta como una vaguada donde las posibilidades de cambio no se agotan. En ello radica la complejidad de aprehender la noción de magma: la potencia creadora que aparece en su máxima expresión en la producción de lo nuevo.

Finalmente, puede considerarse que el magma representa la potencia creadora instituyente de la praxis social. El magma surge desde las significaciones imaginarias sociales (Castoriadis, ob. cit.) que devienen del hacer, actuar, imaginar, y forman la red imaginaria. Las acciones de los hombres, además de ser concebidas como conceptos o definiciones, también se manifiestan en forma de imágenes, figuras, siluetas de las que se deriva alguna significación que no es susceptible de ser concebida por conceptos o descifrada por el campo de la inteligibilidad como logos. 


\section{EL IMAGINARIO SOCIAL: REFLEXIÓN CON CORNELIUS CASTORIADIS \\ Esteban Oliva \\ (PP 100-115)}

En líneas generales lo imaginario como institución, fuerza creadora en el campo histórico social desde los fenómenos sociales, constituye para el investigador un reto a plantearse de nuevo la realidad desde una óptica particular. El individuo puede hacer una vida cargada de realidad, pero debe cambiar y revolucionar los esquemas sobre los cuales reposan sus reflexiones; de lo contrario, será difícil construir una sociedad ensimismada en su cultura instituyente y seguirá viviendo en las entelequias de lo instituido impuesto por los poderosos, y el pensamiento no será tal sino una fantasía para entretenerlo dentro de una burbuja de cristal en la cual cree vivir.

En fin, la actividad, el hacer, la imaginación y los fenómenos sociales le proporcionan fuerza al hombre para emprender lo nuevo, para atreverse a cambiar lo establecido. Hay nuevas significaciones cuando hay actividad imaginativa; quien investiga en referencia a lo imaginario debe comprender que esa noción es un concepto siempre inacabado porque su naturaleza dinámica lo mantiene en constante reedición; el hombre y sus imaginarios, necesariamente, se supeditan a los vertiginosos cambios de su entorno.

\section{CONSIDERACIONES AXIOLÓGICAS FINALES \\ LA IMAGINACIÓN RADICAL: UN MAGMA DE REPRESENTACIONES SOCIALES INSTITUYENTES}

La idea de imaginación radical es una de las categorías centrales en la tesis Institución Imaginaria de la Sociedad de Castoriadis (2003). Con ella propuso una concepción de lo histórico-social sobre la base del principio de no causalidad, desligado de la lógica, el determinismo, del pensamiento estructural-funcionalista. Ni la historia, ni la sociedad, ni el hombre se pueden pensar, interpretar, bajo esquemas rígidos de causalidad, porque en el fondo obedecen a una espontaneidad de autocreación, donde interviene la representación, lo indeterminado, lo indefinible, la pasión, el azar, el hallazgo, lo contingente. Por esta razón, sólo a partir de lo imaginario es posible pensar e interpretar la historia, la sociedad, el individuo; la imaginación es la facultad humana que le permite al individuo crear nuevas formas institucionales, sociales, históricas. Así, la imaginación radical crea imágenes, formas y representaciones mediante las cuales los seres humanos captan el mundo.

La representación consiste en la aptitud que tiene el ser humano de generar una imagen de su propia cultura. Esta imagen lleva consigo una sensibilidad que influye la visión cultural del hombre/mujer y hace que se incline hacia algo. Tal inclinación persigue su conservación como 


\section{EL IMAGINARIO SOCIAL: REFLEXIÓN CON CORNELIUS CASTORIADIS \\ Esteban Oliva \\ (PP 100-115)}

viviente singular y como especie. Tales rasgos son una forma de contingencia en él/ella. A juicio del autor de este artículo, son lo que el metateórico que aquí se sigue llama el “...enigma de un representar-representación originario" (p.181).

Lo anterior es un magma de representaciones, magma de magmas “...modo de organización de una diversidad no susceptible de ser reunida en conjunto, ejemplificada por lo social lo imaginario..." (p.34); es una sensibilidad, cuya asociación es libre, espontánea, en continuo cambio, transformación, alteración; el magma no responden a un orden, un antes o un después. De esta forma, la imaginación radical es una potencialidad creadora con una multiplicidad de infinitas posibilidades. El ser humano es una mezcla de imaginación, reflexión, pasión, deseo y razón; todo ello se resume en el surgimiento permanente de representaciones.

Para Castoriadis (ob.cit.) la imaginación radical es "de origen indominable en su efectividad, indomable por el pensamiento" (p. 246), este pensamiento lo puedo ilustrar en la naturaleza sociable del ser humano que cuando internaliza lo ajeno a él como representación le genera conflictos en la medida en que lo otro es diferente a su propio esquema imaginativo. Además, se encuentra limitado a aceptar la existencia de lo instituido porque es el campo donde su existencia tiene sentido. En la medida que el sujeto reflexiona sobre este molde instituido, podrá ser crítico e inventar maneras de introducir en lo establecido representaciones de su esquema imaginativo. Es un magma de magmas, un continuo movimiento de transformación entre la imaginación radical y lo imaginario como institución que emerge la forma de ser del individuo social. A pesar de que, en un principio, la socialización es impuesta, la misma socialización es el espacio que estimula al individuo a innovar, inventar, convertir lo dado en otro, lo que lo impulsa a cambiar la forma de relacionarse con su futuro.

Con la formulación de la imaginación radical y lo imaginario instituyente, Castoriadis rescata los espacios excluidos, minimizados por el pensamiento estructural funcionalista y recupera el sentido de lo imaginario y la imaginación para teorizar sobre lo meramente humano, lo colectivo y lo social.

Castoriadis (ob.cit.) parte de estas nociones a modo hermenéutica para enfocar los fenómenos sociales que emergen cotidianamente en la dinámica social, ya que su idea se fundamenta en tener presente que lo humano es un mundo infinito de posibilidades, un sistema abierto. Precisamente, cuando el estudio del hombre social es el centro de una investigación; el investigador debe aceptar que el hombre y su mundo consisten en un hacer haciendo que nunca 


\section{EL IMAGINARIO SOCIAL: REFLEXIÓN CON CORNELIUS CASTORIADIS \\ Esteban Oliva \\ (PP 100-115)}

cierra. El mundo humano es construido mediante la vinculación de la imaginación radical como un magma de representaciones sociales instituyentes.

\section{REFERENCIAS}

Acosta Saignes, M. (1983). Estudios de etnología antigua de Venezuela. La Habana, Cuba: Editora Casas de las Américas.

Castoriadis, C. (2003). La institución imaginaria de la sociedad. Título original: L'institutionimaginaire de la société. Traducción del francés al español de Antoni Vicens y Marco Aurelio Galmarini. (2 ${ }^{\mathrm{a}}$ reimpresión). Buenos Aires Argentina: Fábula TusQuets Editores.

Castoriadis, C. (1998a). El ascenso de la insignificancia. Título original: La Monteé de l'insignificante. Traducción del francés al español de Vicente Gómez. Madrid, España: Ediciones Cátedra, S. A.

Castoriadis, C. (1998b). El psicoanálisis, proyecto y elucidación. (Segunda Edición). Argentina, Buenos Aires: Ediciones Nueva Visión.

De Armas Chitty, J. (1993). La independencia de Venezuela. Caracas, Venezuela: Ediciones Grijalbo.

De Unamuno, M. (1967). Del sentimiento trágico de la vida. Madrid-España:Editorial EspasaCalpe.

Freud, S. (1934) Vorlesung. Die Zerlegung der psychischen Persönlichkeit. GesammelteSchriften. (12) pp. 210-234.

Rorty, R. (1993). Ensayos sobre Heidegger y Otros Pensadores contemporáneos. Escritos Filosóficos 2. Título original: Essayson Heidegger and others. Traducción del inglés al español de Jorge Virgil Rubio. Barcelona, España: Ediciones Paidós.

Rutherfurd, E. (2000). London: La novela, un recorrido por 2000 años de historia de Londres. Traducido del Inglés al Español por Camila Battles Madrid, España:Programa Ariadna 1998 de la Unión Europea. Sumas de Letras, S.L.

Santiago, T. (comp.). (2000). Alcances y límites de la racionalidad en el conocimiento y la sociedad. México D.F. Editora Plaza y Valdés C.A. 